\title{
Formulation of electroclinic, ferroelectric and antiferroelectric liquid crystal mixtures suitable for display devices
}

Cite as: AIP Conference Proceedings 1942, 020001 (2018); https://doi.org/10.1063/1.5028580 Published Online: 10 April 2018

Asim Debnath, Debarghya Goswami, and Pradip Kumar Mandal

\section{ARTICLES YOU MAY BE INTERESTED IN}

Preface: 62nd DAE Solid State Physics Symposium

AIP Conference Proceedings 1942, 010001 (2018); https://doi.org/10.1063/1.5028578

Committees: 62nd DAE Solid State Physics Symposium

AIP Conference Proceedings 1942, 010002 (2018); https://doi.org/10.1063/1.5028579

Interface engineered ferrite@ferroelectric core-shell nanostructures: A facile approach to impart superior magneto-electric coupling

AIP Conference Proceedings 1942, 020002 (2018); https://doi.org/10.1063/1.5028581

\section{Conference Proceedings}

Get $30 \%$ off all print proceedings!
Enter Promotion Code $P D D=30$ at checkout

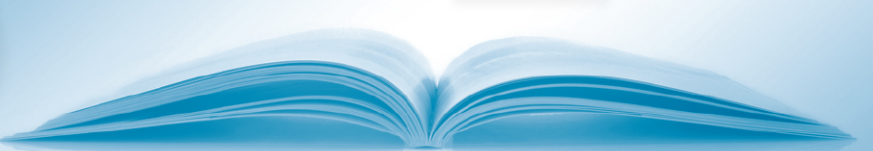




\title{
Formulation of Electroclinic, Ferroelectric and Antiferroelectric Liquid Crystal Mixtures Suitable for Display Devices
}

\author{
Asim Debnath, Debarghya Goswami and Pradip Kumar Mandal ${ }^{\text {a) }}$ \\ Department of Physics, University of North Bengal, Siliguri-734013, WB, India \\ ${ }^{a)}$ Corresponding author: mandal_pradip@yahoo.com
}

\begin{abstract}
Most of the liquid crystal display (LCD) devices starting from simplest wrist watches or calculators to complex laptops or flat TV sets are based on nematics. Although a tremendous improvement in the quality of display as well as reduction of manufacturing cost has taken place over the years, there are many issues which the LC industry is trying hard to address. Ferroelectric liquid crystals (FLC) are of current interest in the LCD industry since among various other advantages FLC based displays have micro-second order switching compared to milli-second order switching in nematic based displays. To meet the market demand much effort has been made to optimize the physical parameters of FLCs, such as temperature range, spontaneous polarization $\left(\mathrm{P}_{\mathrm{S}}\right)$, helical pitch $(\mathrm{p})$, switching time $(\tau)$, tilt angle $(\theta)$ and rotational viscosity $(\gamma)$. Multicomponent mixtures are, therefore, formulated to optimize all the required properties for practical applications since no single FLC compound can satisfy the above requirements. To the best of our knowledge electroclinic, ferroelectric and antiferroelectric liquid crystal mixtures have been formulated first time by any Indian group which have properties suitable for FLC based display devices and at par with mixtures used in the industry.
\end{abstract}

\section{INTRODUCTION}

Now-a-days displays have become a field of tremendous importance as they provide the best means for interface between man and machine. Though large numbers of display systems are presently available, but about $90 \%$ of the market is controlled by the liquid crystal display technology. Again most of the liquid crystal displays use the nematic liquid crystal phase for their operation. Although a tremendous improvement in the quality of display as well as reduction of manufacturing cost has taken place over the years, but there are some disadvantages when nematics are used as display material. Main problem is the low switching time (of the order $20 \mathrm{~ms}$ to $10 \mathrm{~ms}$ ) which results in a low contrast ratio of the display device. Low response also narrows the viewing angle when driven at a high multiplexing ratio which is necessary for high information content display devices. Advance research shows that ferroelectric liquid crystals (FLCs) and antiferroelectric liquid crystals (AFLCs) have potential to become the best choice for displays as they exhibit very fast switching (two to three orders of magnitude faster than the conventional nematic systems) and switching occurs in an in-plane manner, which provides for excellent angles of view and high resolution that were not possible for nematic based displays [1-4]. Besides these ferroelectric (SmC* phase) and antiferroelectric $\left(\mathrm{SmC}_{\mathrm{A}} *\right.$ phase) switching, paraelectric $\mathrm{SmA}^{*}$ liquid crystal phase also exhibit switching in presence of external electric field known as electroclinic effect $[5,6]$.This type of electroclinic switching is usually faster than the in-plane switching in the ferroelectric $\mathrm{SmC}^{*}$ or antiferroelectric $\mathrm{SmC}_{\mathrm{A}}{ }^{*}$ phase which is suitable for fast grayscale display devices, micro-color filters, tunable color filters, switches and optically addressed spatial light modulators etc [7-9]. For these applications much effort has been made to optimize the physical parameters of FLCs, such as temperature range, spontaneous polarization $\left(\mathrm{P}_{\mathrm{S}}\right)$, helical pitch $(\mathrm{p})$, switching time $(\tau)$, tilt angle $(\theta)$ and rotational viscosity $(\gamma)$. Multicomponent mixtures are, therefore, formulated to optimize all the required properties for practical applications since no single FLC compound can satisfy the above requirements. Keeping all these in mind we have prepared electroclinic, ferroelectric and antiferroelectric liquid crystal mixtures, to the best of our knowledge first time by any Indian group, which have properties suitable for FLC based display 
devices and at par with mixtures used in the industry. In this article we report thermal and electro-optical properties of these formulated mixtures.

\section{EXPERIMENTAL METHODS}

Phase behavior and transition temperatures of the mixtures and their constituents were determined by optical polarizing microscopy (OPM) as well as differential scanning calorimeter (DSC) study. For electro-optic measurements polyimide-coated homogeneous dielectric cell, having transparent indium tin oxide (ITO) electrodes of very low resistivity (about $20 \Omega /$ sq.) was used and cell was filled by capillary action with the mixture in isotropic state. Details of the spontaneous polarization, optical tilt angle, switching time measurement and the synchrotron Xray diffraction measurement techniques have been reported before [10-13].

\section{RESULTS AND DISCUSSIONS}

The best way to formulate room temperature fast switching FLC mixture is to add a small amount of chiral dopant having high spontaneous polarization into a low viscous achiral host matrix having SmC phase at or close to room temperature. For host materials phenyl pyrimidine compounds are preferred because they have low viscosity and they increase the tilt angle in mixture which in turn increases the stability. Fluorinated compounds are specially preferred as high polarization dopants because in addition to high polarization they also exhibit low viscosity which substantially decreases the switching speeds of the final mixture. For the preparation of host mixture preparation we used four phenyl pyrimidine compounds, molecular structure and composition of the host matrix is shown in the Fig. 1. As chiral dopants we selected five fluorinated compounds; molecular structures, phase sequences and transition temperatures of them are shown in Table 1.

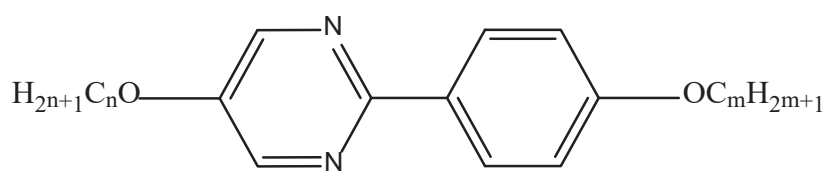

FIGURE 1. Molecular structures of the host matrix: (a) Host 1 (H1: $n=9, m=9)$; (b) Host 2 (H2: $n=9$, m=7); (c) Host 3 (H3: $n=7$, m=9); (d) Host 4 (H4: $n=8, m=6$ ); Host matrix (HM): $\mathrm{H} 1+\mathrm{H} 2+\mathrm{H} 3+\mathrm{H} 4: 20 \%+20 \%+20 \%+40 \%$; Transition temperatures of host mixture: $\mathrm{Cr} 18^{\circ} \mathrm{C} \mathrm{SmC} 69.4^{\circ} \mathrm{C} \mathrm{SmA} 78.7^{\circ} \mathrm{C} \mathrm{N} 81.2^{\circ} \mathrm{C}$ Iso.

\section{Electroclinic Liquid Crystal Mixture}

Although the SmA* phase is paraelectric and the molecules in this phase are normal to the layer plane but when an external electric field is applied parallel to the layers, it induces a tilt of the molecular axes in a plane perpendicular to the field direction. The induction of tilt is due to the coupling of transverse dipole moment of the chiral molecule with applied electric field and is known as electroclinic effect (ECE) as described earlier. The compounds which have high values of spontaneous polarization in $\mathrm{SmC}^{*}$ phase, shows large electroclinic effect due to the induced polarization in $\mathrm{SmA}^{*}$ phase. We have formulated an electroclinic liquid crystal mixture by doping 10 wt $\%$ of dopant DP3, having $\mathrm{P}_{\mathrm{S}} \sim 230 \mathrm{nC} / \mathrm{cm}^{2}$, in the host matrix. Though most of the electroclinic material form ferroelectric $\mathrm{SmC}^{*}$ phase on cooling or crystallizes at room temperature but our mixture exhibit $\mathrm{SmA}^{*}$ phase from $63^{\circ} \mathrm{C}$ down to $17^{\circ} \mathrm{C}$ thus satisfying the basic material need intended for display applications. At low temperatures induced optical tilt $\left(\theta_{\text {opt }}\right)$ show expected linear behaviour only at low electric field [14] and appears to saturate at high field. Whereas at high temperatures we find linear increase in the induced tilt in all values of applied field as shown in Fig. 2(a). Maximum electroclinic coefficient $\left(\mathrm{e}_{\mathrm{C}}\right)$ observed in this mixture is $1.53 \mathrm{deg}$. $\mu \mathrm{mV}^{-1}$. Usually induced tilt is accompanied by a corresponding layer contraction which results in a buckling of the layers that reduces the contrast ratio, high value of which is necessary for good quality of display applications. But our mixture exhibits almost no layer contraction as revealed by high resolution synchrotron studty. At $25^{\circ} \mathrm{C}$, zero field layers spacing was found to be $31.643 \AA$ that contracted to $31.618 \AA$ giving rise to maximum layer shrinkage of $0.08 \%$ (Fig. 
2(b)), thus solves the contrast ratio problem. So no chevron deffect was observed in a display cell. Mixture also exhibit very fast switching, about $21 \mu \mathrm{s}$ at $15 \mathrm{~V}$ driving voltage for a $5 \mu \mathrm{m}$ cell at $20^{\circ} \mathrm{C}$ shown in inset of Fig. 2 (b).
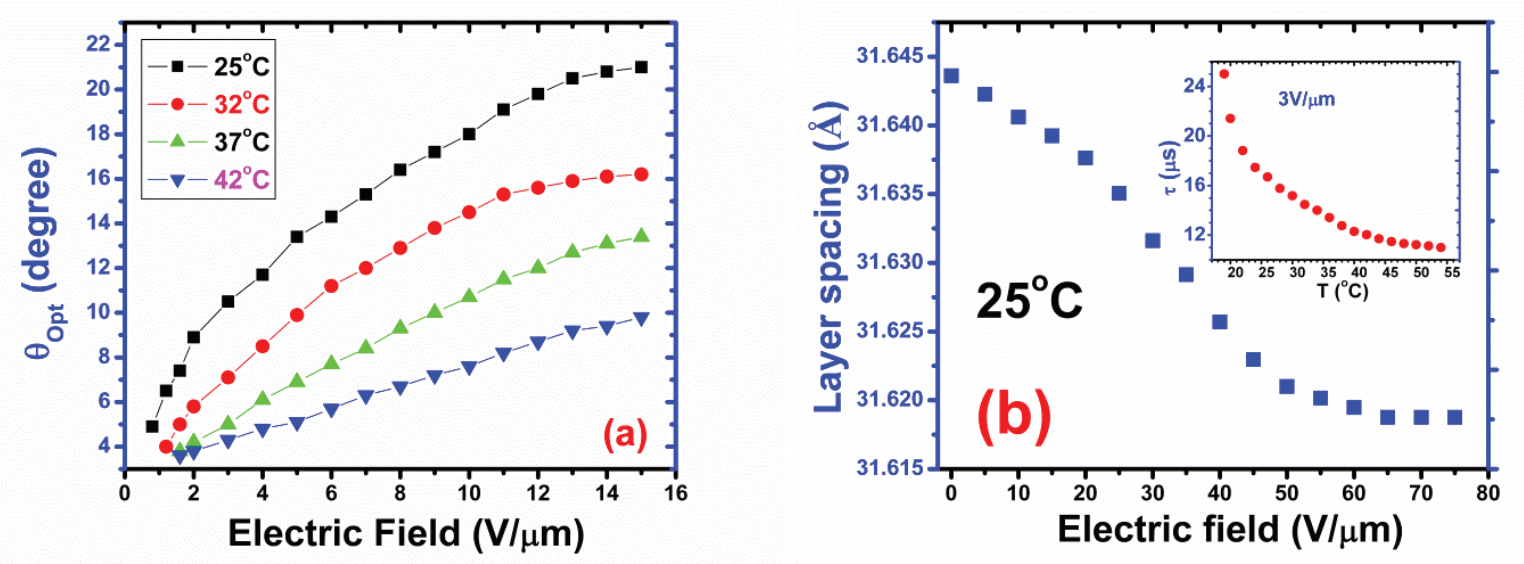

FIGURE 2. Electroclinic Mixture: (a) Electric field variation of optical tilt at some selected temperature (b) Electric field variation of layer spacing at $25^{\circ} \mathrm{C}$ (Inset, Temperature variation of switching time at $3 \mathrm{~V} / \mu \mathrm{m}$ ).

\section{Ferroelectric and Antiferroelectric Liquid Crystal Mixtures}

To formulate ferroelectric/antiferroelectric liquid crystal mixtures we selected five flourinated chiral dopants as shown in Table 1. DP1 is a oligomethylene spacer based flourinated compound which have only ferroelectric SmC* phase whereas other four dopants have nearly similar structures, only difference within the molecular structure is the number and position of fluorine atoms in the benzoate ring of the molecular rigid core and they exhibit antiferroelectric $\mathrm{SmC}_{\mathrm{A}}$, ferroelectric $\mathrm{SmC}^{*}$ and paraelectric $\mathrm{SmA}^{*}$ phases. Though these compounds have ferroelectric/antiferroelectric phase, but the phases are far above the room temperature. However when they were doped in the host matrix, the resulting mixtures were found to exhibit ferroelectric/antiferroelectric phase till $12^{\circ} \mathrm{C}$; below which we could not cool.Composition and phase transition temperatures of the mixtures are shown in Table 2.

It is seen that though the stability of the mixtures (isotropic transition) decreases as compared to the pure dopants but the range of the $\mathrm{SmC}^{*}$ phase increases for all the mixtures, maximum being $93^{\circ}$ in MIX1. So with respect to temperature range formulated mixtures are suitable for display applications. To probe further the suitability of the mixtures in device application, we measured the spontaneous polarization $\left(\mathrm{P}_{\mathrm{S}}\right)$, switching time $(\tau)$, optical tilt angle $(\theta)$ and rotational viscosity $(\gamma)$. Temperature variations of these parameters are shown in Fig. 3.

From Fig. 3(a) one can see that the formulated mixtures exhibit moderately high magnitude of spontaneous polarization $\left(\mathrm{P}_{\mathrm{S}}\right)$ which is very important for practical applications. Because low values of $\mathrm{P}_{\mathrm{S}}$ requires high electric field for their operation and high $\mathrm{P}_{\mathrm{S}}$ build up a large internal field in the devices which makes polarization revesal difficult that is also undesireable. For MIX1, MIX2, MIX3, MIX4 and MIX5 magnitudes of $\mathrm{P}_{\mathrm{S}}$ are in the range of $136-122 \mathrm{nC} / \mathrm{cm}^{2}, 145-93 \mathrm{nC} / \mathrm{cm}^{2}, 135-110 \mathrm{nC} / \mathrm{cm}^{2}, 120-82 \mathrm{nC} / \mathrm{cm}^{2}$ and $130-57 \mathrm{nC} / \mathrm{cm}^{2}$ respectively. Such type of moderately high $\mathrm{P}_{\mathrm{S}}$ value is suitable for thin-film transistor-based active matrix display devices.

Tilt angle $(\theta)$, the angle made by the molecular director with the smectic layer normal is directly connected with the contrast ratio of the display devices. Current reseach shows that the liquid crystal materials which have tilt angle greater than $35^{\circ}$ are suitable for practical applications and maximum contrast ratio is achieved when the tilt of the molecules becomes $45^{\circ}$ [4]. Our mixtures are found to exhibit high values of $\theta$ and decreases very slowly with temperature from $42-38^{\circ}, 41-24^{\circ}, 40-34^{\circ}, 38-22^{\circ}$ and $40-26^{\circ}$ for MIX1, MIX2, MIX3, MIX4 and MIX5 respectively (see Fig. 3(b)) which will result in relatively constant contrast and brightness in the display devices. 
TABLE 1. Molecular Structure, Phase Transition Temperature of Dopants

\section{Dopant 1 (DP1):}

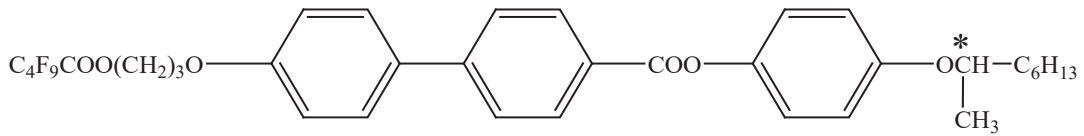

$\mathrm{Cr} 79.8^{\circ} \mathrm{C} \mathrm{SmC}^{*} 134.1^{\circ} \mathrm{C}$ Iso

Dopant 2 (DP2):

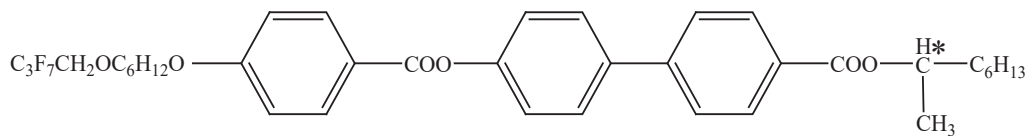

$\mathrm{Cr} 60.5^{\circ} \mathrm{C} \mathrm{SmC}_{\mathrm{A}}{ }^{*} 94.7^{\circ} \mathrm{C} \mathrm{SmC}^{*} 124.8^{\circ} \mathrm{C} \mathrm{SmA}^{*} 126.3^{\circ} \mathrm{C}$ Iso

Dopant 3 (DP3):

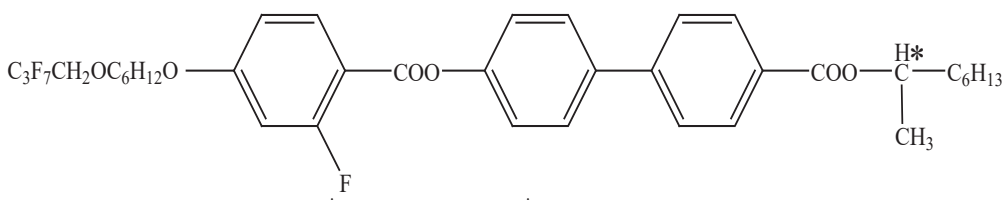

$\mathrm{Cr} 42.2^{\circ} \mathrm{C} \mathrm{SmC}_{\mathrm{A}}{ }^{*} 73.9^{\circ} \mathrm{C} \mathrm{SmC}^{*} 103.7^{\circ} \mathrm{C} \mathrm{SmA}^{*} 108.5^{\circ} \mathrm{C}$ Iso

Dopant 4 (DP4):

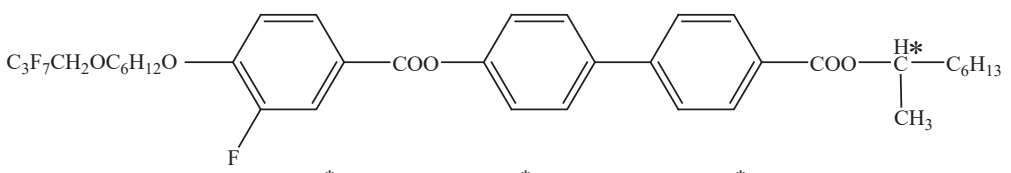

$\mathrm{Cr} 57.3^{\circ} \mathrm{C} \mathrm{SmC}_{\mathrm{A}}^{*} 80.1^{\circ} \mathrm{C} \mathrm{SmC}^{*} 108.5^{\circ} \mathrm{C} \mathrm{SmA}^{*} 112.7^{\circ} \mathrm{C}$ Iso

Dopant 5 (DP5):

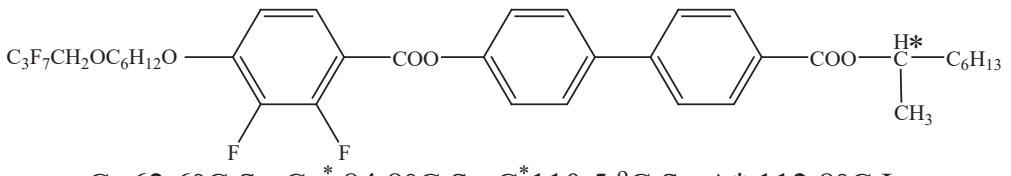

$\mathrm{Cr} 62.6^{\circ} \mathrm{C} \mathrm{SmC}_{\mathrm{A}}^{*} 84.8^{\circ} \mathrm{C} \mathrm{SmC}^{*} 110.5^{\circ} \mathrm{C} \mathrm{SmA}^{*} 112.8^{\circ} \mathrm{C}$ Iso

TABLE 2. Composition and Phase Transition Temperatures of the mixtures

\begin{tabular}{|c|c|c|}
\hline Mixture & Composition & Phase Transition Temperatures \\
\hline MIX1 & $\mathrm{HM}+\mathrm{DP} 1: 40 \mathrm{wt} \%+60 \mathrm{wt} \%$ & $\mathrm{Cr}<12^{\circ} \mathrm{C} \mathrm{SmC}^{*} 105^{\circ} \mathrm{C}$ Iso \\
\hline MIX2 & HM+DP2: $60 w t \%+40 w t \%$ & $\mathrm{Cr}<12^{\circ} \mathrm{C} \mathrm{SmC}_{\mathrm{A}}^{*} 37^{\circ} \mathrm{C} \mathrm{SmC}^{*} 97.5^{\circ} \mathrm{C} \mathrm{SmA}^{*} 112.3^{\circ} \mathrm{C}$ Iso \\
\hline MIX3 & HM+DP3: $60 w t \%+40 w t \%$ & $\mathrm{Cr}<12^{\circ} \mathrm{C} \mathrm{SmC}^{*} 57.2^{\circ} \mathrm{C} \mathrm{SmA}^{*} 93.8^{\circ} \mathrm{C}$ Iso \\
\hline MIX4 & $\mathrm{HM}+\mathrm{DP} 4: 60 \mathrm{wt} \%+40 \mathrm{wt} \%$ & $\mathrm{Cr}<12^{\circ} \mathrm{C} \mathrm{SmC}^{*} 89^{\circ} \mathrm{C} \mathrm{SmA}^{*} 108^{\circ} \mathrm{C}$ Iso \\
\hline MIX5 & $\mathrm{HM}+\mathrm{DP} 5: 60 \mathrm{wt} \%+40 \mathrm{wt} \%$ & $\mathrm{Cr}<12^{\circ} \mathrm{C} \mathrm{SmC}_{\mathrm{A}}^{*} 42^{\circ} \mathrm{C} \mathrm{SmC}^{*} 97^{\circ} \mathrm{C} \mathrm{SmA}^{*} 104.5^{\circ} \mathrm{C}$ Iso \\
\hline
\end{tabular}

Rotatoinal viscosity $(\gamma)$ is related with the rotations of the molecules about a cone in presence of applied electric field and low value of $\gamma$ is desired for fast swtiching display devices. Our mixtures exhibit low viscosity (0.14$0.03 \mathrm{~N}-\mathrm{sec} / \mathrm{m}^{2}, 1.87-0.21 \mathrm{~N}-\mathrm{sec} / \mathrm{m}^{2}, 1.53-0.41 \mathrm{~N}-\mathrm{sec} / \mathrm{m}^{2}, 1.01-0.01 \mathrm{~N}-\mathrm{sec} / \mathrm{m}^{2}$ and $0.74-0.06 \mathrm{~N}-\mathrm{sec} / \mathrm{m}^{2}$ for MIX1, MIX2, MIX3, MIX4 and MIX5 respectively) because of the presence of low viscous pyrimidine based host matrix as well as the presence of fluorinated chiral dopant. Their temperature variation is shown in Fig. 3(c). 
From application point of view switching time is the most importantant parameter as lower is the switching time faster will be the electro-optical response, necessary criteria for any high speed grey scale display devices. Submillisecond switching speed is desired to afford a video rate time sequential colour micro-display. Because of low viscosity and moderately high spontaneous polarization of the mixtures they found to exhibit very fast switching from $100-10 \mu \mathrm{s}, 320-60 \mu \mathrm{s}, 280-95 \mu \mathrm{s}, 210-45 \mu \mathrm{s}$ and $150-30 \mu \mathrm{s}$ for MIX1, MIX2, MIX3, MIX4 and MIX5 respectively. Thus the formulated mixtures show relatively fast switching which is the basic need for display applications. Important display parameters of other mixtures have been summarized in Table 3 and their display properties are comparable to commercially available mixtures from E. Merk (ZLI-3234, ZLI-4237-100) [15], Chisso (CS4001) [16].
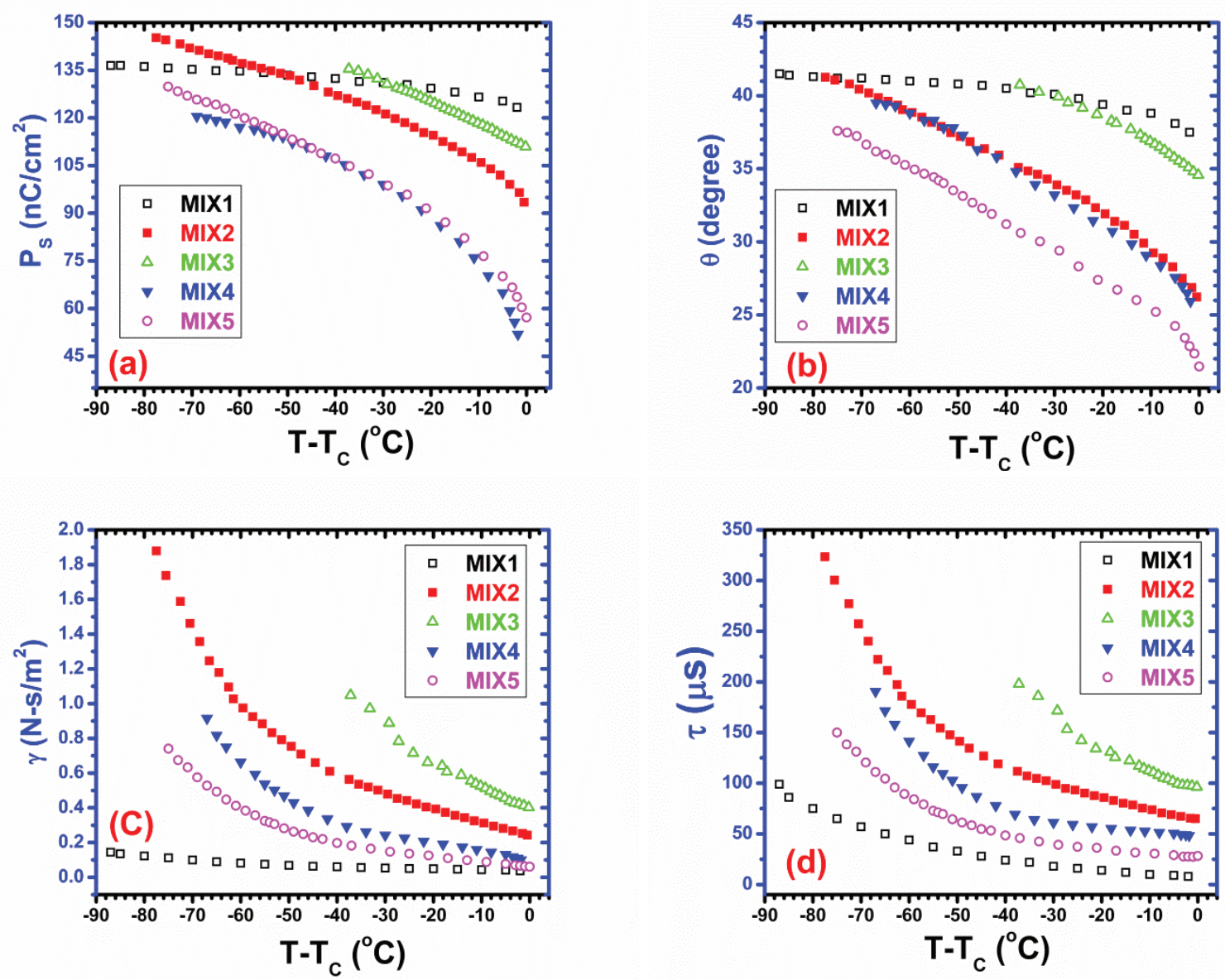

FIGURE 3. Temperature variation of (a) spontaneous polarization $\left(\mathrm{P}_{\mathrm{S}}\right)$, (b) optical tilt angle $(\theta)$, (c) rotational viscosity $\left(\gamma_{\varphi}\right)$ and (d) switching time $(\tau)$ of MIX1, MIX2, MIX3, MIX4 and MIX5. [T $\mathrm{T}_{\mathrm{C}}: \mathrm{SmC}^{*}-\mathrm{SmA}^{*}$ transition temperature for MIX2-MIX5 and for MIX1, $\mathrm{T}_{\mathrm{C}}: \mathrm{SmC}^{*}$-Iso transition temperature]. 
TABLE 3. Comparison of important display parameters of the formulated mixtures at $20^{\circ} \mathrm{C}$ with commercial mixtures

\begin{tabular}{llccc}
\hline Mixture & $\mathrm{P}_{\mathrm{S}}\left(\mathrm{nC} / \mathrm{cm}^{2}\right)$ & $\theta\left({ }^{\circ}\right)$ & $\gamma\left(\mathrm{N}-\mathrm{sec} / \mathrm{m}^{2}\right)$ & $\tau(\mu \mathrm{s})$ \\
\hline MIX1 & 136 & 42 & 0.14 & 85 \\
MIX2 & 145 & 41.2 & 1.87 & 323 \\
MIX3 & 135 & 40.7 & 1.53 & 283 \\
MIX4 & 120 & 39.5 & 1.00 & 207 \\
MIX5 & 129 & 37.5 & 0.74 & 150 \\
ZLI-3234* & 25 & - & - & 65 \\
ZLI-4237-100* & 25 & - & 0.50 & 500 \\
CS4001\# & 79.7 & 24.5 & - & 79.5 \\
\hline
\end{tabular}

* quoted parameters at $30^{\circ} \mathrm{C}[15]$, \# parameters at $25^{\circ} \mathrm{C}[16]$ of commercial mixtures

\section{CONCLUSIONS}

In summary, one electroclinic, three ferroelectric and two antiferroelectric mixtures have been formulated. The electroclinic mixture shows very high EC coefficient, very fast switching and negligibly small layer contraction. and the ferroelectric mixture, MIX1, is found to be most suitable for display applications. Its temperature range and switching time are comparable to commercially available mixtures.

\section{ACKNOWLEDGEMENTS}

Funding from BRNS, DAE and DST under India@DESY program is thankfully acknowledged.

\section{REFERENCES}

1. $\quad$ N. A. Clark and S. T. Lagerwall, Appl. Phys. Letters 36, 899-902 (1980).

2. M. Hird, Liq. Crystal 38, 1467-1493 (2011).

3. A. D. L Chandani, Y. Ouchi, H. Takezoe, A. Fukuda, K. Tarashima, K. Furukawa and A. Kishi, Jpn. J. Appl. Physics, Part 2, 28, L1261-L1264 (1989).

4. K. D’Havé, P. Rudquist, S. T. Lagerwall, H. pauwels, W. Drzewinski and R. Dabrowski, Appl. Phys. Letters 76, 3528-3530 (2000).

5. S. Garoff and R. B. Meyer, Phys. Rev. Letters 38, 848-851 (1977).

6. S. Garoff and R. B. Meyer, Phys. Rev. A 19, 338-347 (1979).

7. G. Andersson, I. Dahl, L. Komitov, S. T. Lagerwall, K. Sharp, and B. Stebler, J. Appl. Physics 66, $4983-4995$ (1989).

8. I. Abdulhalim, G. Moddel, and K. M. Johnson, Appl. Phys. Letters 55, 1603-1605 (1989).

9. L. Beresnev and W. Haase, Opt. Materials 9, 201-211 (1998).

10. A. Debnath, D. Sinha, and P. K. Mandal, J. Appl. Physics 119, 124103 (1-4) (2016).

11. A. Debnath and P. K. Mandal, J. Mol. Liquids 221, 287-291 (2016).

12. A. Debnath, P. K. Mandal, D. Weglowska and R. Dabrowski, RSC Advances 6, 84369-84378 (2016).

13. A. Debnath and P. K Mandal, Liq. Crystal, Published online: 29 May 2017.

14. G. Andersson, I. Dahl, W. Kuczynski, S. T. Lagerwall, K. Skarp, and B. Stebler, Ferroelectrics 84, 285 (1988).

15. B. Bahadur, Liquid crystals-applications and uses, (World Scientific, New Jersey, 1990).

16. K. D’Havé, Application of Antiferroelectric Liquid Crystals with High Tilt (Ph.D. Thesis, Chalmers Universiy of Technology, Gothenburg, 2002), pp. 99. 